\title{
Linear Matrix Inequality Based Fuzzy Synchronization for Fractional Order Chaos
}

\author{
Bin Wang, Hongbo Cao, Yuzhu Wang, and Delan Zhu \\ Department of Electrical Engineering, Northwest A\&F University, Yangling 712100, China \\ Correspondence should be addressed to Delan Zhu; dlzhu@126.com
}

Received 8 December 2014; Accepted 27 March 2015

Academic Editor: Evangelos J. Sapountzakis

Copyright (C) 2015 Bin Wang et al. This is an open access article distributed under the Creative Commons Attribution License, which permits unrestricted use, distribution, and reproduction in any medium, provided the original work is properly cited.

This paper investigates fuzzy synchronization for fractional order chaos via linear matrix inequality. Based on generalized TakagiSugeno fuzzy model, one efficient stability condition for fractional order chaos synchronization or antisynchronization is given. The fractional order stability condition is transformed into a set of linear matrix inequalities and the rigorous proof details are presented. Furthermore, through fractional order linear time-invariant (LTI) interval theory, the approach is developed for fractional order chaos synchronization regardless of the system with uncertain parameters. Three typical examples, including synchronization between an integer order three-dimensional (3D) chaos and a fractional order 3D chaos, anti-synchronization of two fractional order hyperchaos, and the synchronization between an integer order 3D chaos and a fractional order 4D chaos, are employed to verify the theoretical results.

\section{Introduction}

Fractional order calculus can date back to 300 years ago. Nevertheless, application of fractional order calculus into actual project has not attracted much attention until recent decades [1-4]. It is widely recognized that many systems by introducing fractional order calculus can be better modeled compared with integer order calculus, especially for systems with memory and hereditary factors [5-7]. Many actual projects can be elegantly described with fractional calculus. For example, power system [8], physical system [9], chemical system [10], mechanical system [11], and so on.

As we all know, integer order chaos is universal in practical systems. In recent years, there are also many reports on new fractional order chaos, for example, a new fractional order hyperchaos [12], fractional order Liu chaos [13], fractional order unified chaos [14], and a new double wing fractional order chaos [15]. In particular, because of the application in secure communication and signal processing, chaos synchronization has become a hot topic.

Numerous studies about integer order chaos synchronization have been presented [16-18], while fractional order chaos synchronization in secure communication and signal processing has more advantages than integer order chaos [1921]. However, could fractional order chaos be well synchronized? It is worth studying. Until now, many synchronous strategies have been presented for the synchronization of fractional order chaos such as pinning synchronization [22], function projective synchronization [23], adaptive synchronization [24], and finite-time synchronization [25].

As we all know, fuzzy method is an effective and robust control strategy, and it can process uncertain parameters well. There is a lot of work reported in fuzzy control and synchronization of chaos. For example, in [26], a new controller is proposed via fuzzy logic for real-time substructuring applications, and the effectiveness is proved by evaluating the response of a framework fixed at one of the beam joints for ElCentro earthquake. In [27], by introducing fuzzy techniques, a command-filtered adaptive fuzzy neural network backstepping control law is presented to restrain chaotic oscillation of marine power system. In [28], a fuzzy adaptive control law is proposed for the projective synchronization of unknown multivariable chaos. There also has been a wide application of integer order chaos fuzzy synchronization based on linear 
matrix inequality (LMI). In [29], by employing LMI method, a new fuzzy controller based on Takagi-Sugeno (T-S) fuzzy model is designed for chaos synchronization of two Rikitake generator systems. In [30], the authors focus on the observer design for application in secure communications procedure and chaos synchronization based on T-S fuzzy model, and the sufficient stable condition is given as LMI. In [31], T-S fuzzy receding horizon $\mathrm{H}$-infinity synchronization (TSFRHHS) approach is proposed and a novel set of LMI conditions is given. And the scheme is applied to synchronize Lorenz meteorological chaos. However, as we all know, fractional order chaos has different controllability region with chaos of integer order. Can fuzzy synchronization of fractional order chaos be performed via LMI? If the hypothesis is true, what are the specific mathematical derivation and application conditions? There are no relevant results yet. It is still an open problem.

In light of the above analysis, there are several advantages which make our study attractive. Firstly, based on generalized Takagi-Sugeno fuzzy model and fractional order stability theorem, one efficient stability condition for fractional order chaos synchronization or antisynchronization is given and the rigorous proof details are presented. Secondly, through the LTI interval theory for fractional order system, the approach is developed for fractional order chaos synchronization regardless the system with uncertain parameters. Thirdly, antisynchronization of fractional order chaos can be easily implemented by this approach. Finally, numerical simulations agree well with theoretical results.

The contents of our paper are given as follows. Some necessary preliminaries are presented in Section 2. Section 3 introduces the system description and fuzzy synchronization design. Three typical examples are employed to verify the validity of the designed approach and numerical simulation results are also included in Section 4. Section 5 draws the conclusions.

\section{Mathematical Preparation}

2.1. LTI Interval Theory. The LTI interval fractional order system is presented:

$$
\frac{d^{q} x}{d t^{q}}=\widetilde{A} x(t)
$$

where $q(0<q \leq 1)$ are the orders of system (1) and $\widetilde{A}$ is the uncertainty meeting, $\widetilde{A} \in N\left[A^{l}, A^{u}\right]=\left\{\widetilde{A} \in R^{n \times n} \mid a_{i j}^{l} \leq\right.$ $\left.a_{i j} \leq a^{u}{ }_{i j}, i, j=1, \ldots, n\right\}$, where $A^{l}$ and $A^{u}$ are the lower and upper bounds, respectively.

The matrix $\widetilde{A}$ is equivalent to

$$
\widetilde{A}=A_{0 i}+E \sum F,
$$

where

$$
\begin{gathered}
A_{0 i}=\frac{1}{2}\left(A_{i}^{l}+A_{i}^{u}\right), \\
\sum \in \sum^{*} \\
=\left\{\sum_{i} \in R^{n \times n} \mid \sum_{i}=\operatorname{diag}\left(\varepsilon_{11}, \ldots, \varepsilon_{1 n}, \ldots, \varepsilon_{n 1}, \ldots, \varepsilon_{n n}\right),\right. \\
E=\left(\sqrt{h_{11}} e_{1}, \ldots, \sqrt{h_{1 n}} e_{1}, \ldots, \sqrt{h_{n 1}} e_{n}, \ldots, \sqrt{h_{n n}} e_{n}\right), \\
F=\left(\sqrt{h_{11}} e_{1}, \ldots, \sqrt{h_{1 n}} e_{n}, \ldots, \sqrt{h_{n 1}} e_{1}, \ldots, \sqrt{h_{n n}} e_{n}\right)^{T}, \\
H=\left(h_{i j}\right)_{n \times n}=H_{i}=\frac{1}{2}\left(A^{u}{ }_{i}-A_{i}^{l}\right), \quad e_{i}(i=1, \ldots, n)
\end{gathered}
$$

is the $n \times n$ identity matrix $i$ th column.

Noticing that, for any $i$ and $\sum \in \Sigma^{*}$, one has

$$
\sum \sum^{T}=\sum^{T} \sum \leq I \quad(I \text { is } n \times n \text { identity matrix }) .
$$

2.2. Generalized Takagi-Sugeno Fuzzy Model. For a continuous nonlinear fractional order system, the generalized Takagi-Sugeno fuzzy model is shown as

$$
\begin{aligned}
& \text { Rule } R^{i}: \operatorname{IF} z_{1}(t) \text { is } M_{i 1} \cdots z_{n}(t) \text { is } M_{\text {in }} \\
& \operatorname{THEN} \frac{d^{q} x}{d t^{q}}=A_{i} x(t)+B_{i} u(t) \quad(i=1,2, \ldots, r),
\end{aligned}
$$

where fuzzy set is $M_{i j}(j=1,2, \ldots, n)$ and IF-THEN rules number is $r$, system state vector is $x(t) \in R^{n}, A_{i} \in R^{n \times n}$, the premise variables are $z(t)=\left[z_{1}(t), z_{2}(t), \ldots, z_{n}(t)\right]$, and $u(t)$ is control variable. Now we can get the generalized TakagiSugeno fuzzy model:

$$
\frac{d^{q} x}{d t^{q}}=\sum_{i=1}^{r} h_{i}(z(t)) A_{i} x(t)+\sum_{i=1}^{r} h_{i}(z(t)) B_{i} u(t)
$$

where

$$
\begin{aligned}
h_{i}(z(t))= & \frac{\prod_{j=1}^{n} M_{i j}\left(z_{j}(t)\right)}{\sum_{i=1}^{r} \prod_{j=1}^{n} M_{i j}\left(z_{j}(t)\right)} \geq 0, \\
& \sum_{i=1}^{r} h_{i}(z(t))=1,
\end{aligned}
$$

where $h_{i}(z(t))$ represents IF-THEN rule normalized weight, with $M_{i j}(z(t))$ being the grade of membership of $z_{j}(t)$ in $M_{i j}$. 
2.3. Parallel Distributed Compensation (PDC) Control Law. There are two basic steps of PDC method. Firstly, each subsystem of the fuzzy model needs to complete local state feedback controller design. Then, the membership functions determine the weights of each local state feedback controller. So the local controllers form global fuzzy controller.

Therefore, the state feedback controller is given as

Rule $R^{i}$ : IF $z_{1}(t)$ is $M_{i 1} \cdots z_{n}(t)$ is $M_{\text {in }}$

$$
\text { THEN } u(t)=K_{i} x(t) \quad(i=1,2, \ldots, r) .
$$

The PDC control law is expressed in the following:

$$
u(t)=\sum_{j=1}^{r} h_{j}(z(t)) K_{j} x(t)
$$

where $K_{i}$ is the controller gain.

Submitting (9) into (6), one gets

$$
\begin{aligned}
\frac{d^{q} x}{d t^{q}}=\sum_{i=1}^{r} & h_{i}(z(t)) A_{i} x(t) \\
& +\sum_{i=1}^{r} h_{i}(z(t)) B_{i} \sum_{j=1}^{r} h_{j}(z(t)) K_{j} x(t) .
\end{aligned}
$$

To simplify (10), make the following variants:

$$
\sum_{i=1}^{r} h_{i} A_{i}=h_{1} A_{1}+h_{2} A_{2}+\cdots+h_{r} A_{r} .
$$

Taking into account $\sum_{i=1}^{r} h_{i}(z(t))=1$ in (7), (11) could be presented as

$$
\begin{aligned}
\sum_{i=1}^{r} h_{i} A_{i}= & h_{1}\left(h_{1}+h_{2}+\cdots+h_{r}\right) A_{1}+\cdots \\
& +h_{r}\left(h_{1}+h_{2}+\cdots+h_{r}\right) A_{r} \\
= & \left(h_{1}^{2}+h_{1} h_{2}+\cdots+h_{1} h_{r}\right) A_{1}+\cdots \\
& +\left(h_{r} h_{1}+h_{r} h_{2}+\cdots+h_{r}^{2}\right) A_{r} \\
= & \sum_{i=1}^{r} \sum_{j=1}^{r} h_{i} h_{j} A_{i} .
\end{aligned}
$$

In (10), $\sum_{i=1}^{r} h_{i} B_{i} \sum_{j=1}^{r} h_{j} K_{j}$ can be equivalent to

$$
\begin{aligned}
\sum_{i=1}^{r} h_{i} & B_{i} \sum_{j=1}^{r} h_{j} K_{j} \\
= & \left(h_{1} B_{1}+h_{2} B_{2}+\cdots+h_{r} B_{r}\right)\left(h_{1} K_{1}+h_{2} K_{2}+\cdots+h_{r} K_{r}\right) \\
= & h_{1} B_{1}\left(h_{1} K_{1}+\cdots+h_{r} K_{r}\right)+\cdots \\
& +h_{r} B_{r}\left(h_{1} K_{1}+h_{2} K_{2}+\cdots+h_{r} K_{r}\right) \\
= & h_{1}{ }^{2} B_{1} K_{1}+h_{2}{ }^{2} B_{2} K_{2}+\cdots+h_{i}{ }^{2} B_{i} K_{i}+\cdots \\
& +h_{r}{ }^{2} B_{r} K_{r}+h_{1}\left(h_{2} K_{2}+h_{3} K_{3}+\cdots+h_{r} K_{r}\right) B_{1} \\
& +h_{2}\left(h_{3} K_{3}+\cdots+h_{r} K_{r}\right) B_{2}+\cdots
\end{aligned}
$$

$$
\begin{aligned}
& +h_{i}\left(h_{i+1} K_{i+1}+\cdots+h_{r} K_{r}\right) B_{i}+\cdots \\
& +h_{r-1} h_{r} K_{r} B_{r-1} \\
& +h_{2} h_{1} K_{1} B_{2}+h_{3}\left(h_{2} K_{2}+h_{1} K_{1}\right) B_{3}+\cdots \\
& +h_{j}\left(h_{j-1} K_{j-1}+h_{j-2} K_{j-2}+\cdots+h_{1} K_{1}\right) B_{j}+\cdots \\
& +h_{r}\left(h_{r-1} K_{r-1}+h_{r-2} K_{r-2}+\cdots+h_{1} K_{1}\right) B_{r} \\
& =\sum_{i=1}^{r} h_{i}^{2} B_{i} K_{j}+\sum_{i<j}^{r} h_{i} h_{j} K_{j} B_{i}+\sum_{i>j}^{r} h_{i} h_{j} K_{j} B_{i} \\
& =\sum_{i=1}^{r} \sum_{j=1}^{r} h_{i} h_{j} B_{i} K_{j} .
\end{aligned}
$$

Substituting (12) and (13) into (10), one has

$$
\frac{d^{q} x}{d t^{q}}=\sum_{i=1}^{r} \sum_{j=1}^{r} h_{i}(z(t)) h_{j}(z(t))\left(A_{i}+B_{i} K_{j}\right) x(t) .
$$

Consider uncertain system parameters of fractional order system (14); that is, $A_{i}$ is uncertain coefficient matrix. From (2), system (14) could be rewritten in the following form:

$$
\frac{d^{q} x}{d t^{q}}=\sum_{i=1}^{r} \sum_{j=1}^{r} h_{i}(z(t)) h_{j}(z(t))\left(A_{0 i}+E \sum F+B_{i} K_{j}\right) x(t) .
$$

\section{Generalized Synchronization}

3.1. System Description. The Caputo fractional derivative has a popular application in engineering, which is adopted in this paper. Considering a class of fractional order chaos, the drive and response systems are described as follows, respectively:

$$
\begin{gathered}
D^{\alpha} x=\widetilde{A} x(t)+f(x), \\
D^{\beta} y=\widetilde{C} y(t)+g(y)+u(t),
\end{gathered}
$$

where $x, y \in R^{n}$ are drive and response system state vectors, respectively. $f, g: R^{n} \rightarrow R^{n}$ is a continuous vector function for the system. $\alpha$ and $\beta$ are $n \times 1$ vectors representing the drive and response system chaotic orders. $\widetilde{A}$ and $\widetilde{C}$ are the linear part of drive and response system parameter matrices. The controller $u(t)$ needs to be designed.

The goal is to design a synchronous effective controller $u(t)$, which can make response system (17) track the trajectories of drive system (16) and synchronization between the two systems is finally achieved.

We define the synchronization error as

$$
e=y-\chi x,
$$

where $\chi$ is an arbitrary regulating factor and $\chi \in R$. Here, the controller $u(t)$ is divided into two subcontrollers $u_{1}(t)$ and $u_{2}(t)$; that is, $u(t)=u_{1}(t)+u_{2}(t)$. The subcontroller $u_{1}(t)$ is designed as

$$
u_{1}(t)=D^{\beta}(\chi x)
$$


Submitting (19) to (17), one can get the dynamical error system:

$$
D^{\beta} e=\widetilde{C} y+g(y)+u_{2}(t) .
$$

According to the Takagi-Sugeno fuzzy model, we can rewrite dynamical error system (20) as

$$
\frac{d^{q} e}{d t}=\sum_{i=1}^{r} h_{i}(z(t)) C_{i} y(t)+\sum_{i=1}^{r} h_{i}(z(t)) B_{i} u_{2}(t) .
$$

3.2. Fuzzy Controller Design. According to Section 2.3, using the PDC control law, the subcontroller $u_{2}(t)$ is composed as

$$
u_{2}(t)=\sum_{j=1}^{r} h_{j}(z(t)) K_{j} y(t)
$$

where $K_{j}$ is the controller gain.

Substituting (22) into (21), one has

$$
\begin{aligned}
\frac{d^{q} e}{d t^{q}}= & \sum_{i=1}^{r} h_{i}(z(t)) C_{i} y(t)+\sum_{i=1}^{r} h_{i}(z(t)) B_{i} u_{2}(t) \\
= & \sum_{i=1}^{r} h_{i}(z(t)) C_{i} y(t) \\
& +\sum_{i=1}^{r} h_{i}(z(t)) B_{i} \sum_{j=1}^{r} h_{j}(z(t)) K_{j} y(t) \\
= & \sum_{i=1}^{r} \sum_{j=1}^{r} h_{i}(z(t)) h_{j}(z(t))\left(C_{i}+B_{i} K_{j}\right) y(t) \\
= & \sum_{i=1}^{r} \sum_{j=1}^{r} h_{i}(z(t)) h_{j}(z(t))\left(C_{0 i}+E \sum F+B_{i} K_{j}\right) y(t) .
\end{aligned}
$$

Combining (19) and (22), we can get the total controller:

$$
\begin{aligned}
u(t) & =u_{1}(t)+u_{2}(t) \\
& =D^{\beta}(\chi x(t))+\sum_{j=1}^{r} h_{j}(z(t)) K_{j} y(t) .
\end{aligned}
$$

Lemma 1 (see [32]). The following inequality holds when $\eta$ is a positive constant and matrices $X, Y$, and $R$ have appropriate dimensions:

$$
X Y+(X Y)^{T} \leq \eta X R^{T}+\eta^{-1} Y^{T} Y .
$$

Lemma 2 (see [33]). Fractional order system (23) will be globally asymptotically stable if the system with real positive symmetric $P$ matrix and semidefinite positive $Q$ matrix is meeting the following condition:

$$
\widetilde{A^{T}} P+P \widetilde{A}=-Q
$$

Based on Lemma 2, a more flexible stability condition can be described as follows.
Lemma 3. Fractional order system (23) will be globally asymptotically stable if there exists a real positive definite symmetric matrix $P$ meeting $J=x^{T} P\left(d^{q} x / d t^{q}\right) \leq 0$. The $J$ function $J=x^{T} P\left(d^{q} x / d t^{q}\right) \leq 0$ is equivalent to

$$
J_{0}=x^{T} P \frac{d^{q} x}{d t^{q}}+\left(\frac{d^{q} x}{d t^{q}}\right)^{T} P x \leq 0 .
$$

Proof. From Lemma 2, one has

$$
\widetilde{A^{T}} P+P \widetilde{A}=-Q
$$

We can easily get the equivalent transformation of (28) as follows:

$$
x^{T}\left(\widetilde{A^{T}} P+P \widetilde{A}\right) x=-x^{T} Q x,
$$

where $Q$ is semidefinite positive matrix. So the following inequality holds:

$$
x^{T}\left(\widetilde{A^{T}} P+P \widetilde{A}\right) x=-x^{T} Q x \leq 0 .
$$

Substituting (1) into (30), one has

$$
x^{T} P \frac{d^{q} x}{d t^{q}}+\left(\frac{d^{q} x}{d t^{q}}\right)^{T} P x \leq 0 .
$$

Matrix $P$ is given as

$$
P=\left[\begin{array}{cccc}
a_{11} & a_{12} & \cdots & a_{1 n} \\
a_{21} & a_{22} & \cdots & a_{2 n} \\
\vdots & \vdots & \ddots & \vdots \\
a_{n 1} & a_{n 2} & \cdots & a_{n n}
\end{array}\right]
$$
(32) to (31):

$$
\sum_{i, j=1}^{n} a_{i j} x_{j} \frac{d^{q} x_{i}}{d t^{q}}+\sum_{i, j=1}^{n} a_{i j} x_{i} \frac{d^{q} x_{j}}{d t^{q}} \leq 0
$$

where $a_{i j}=a_{j i}$ (for all $\left.i, j\right)$.

Therefore, we can rewrite (33) as follows:

$$
\begin{aligned}
& \sum_{i, j=1}^{n} a_{i j} x_{i} \frac{d^{q} x_{j}}{d t^{q}}+\sum_{i, j=1}^{n} a_{i j} x_{j} \frac{d^{q} x_{i}}{d t^{q}} \\
& =2 \sum_{i, j=1}^{n} a_{i j} x_{j} \frac{d^{q} x_{i}}{d t^{q}} \\
& =2 x^{T} P \frac{d^{q} x}{d t^{q}} \\
& =2\left(\frac{d^{q} x}{d t^{q}}\right)^{T} P x
\end{aligned}
$$

$\leq 0$.

The proof is finished. 
Theorem 4. When response system (17) is driven by the controller (24), suppose there exists a constant $\eta>0$ and matrix $P$ is positive, by selecting controller gains $K_{1}, K_{2}, K_{3}, K_{4}$ meeting the inequality following; then dynamical error system (23) will be stable and converge to zero so that the synchronization is achieved. Consider

$$
\begin{gathered}
G_{i i}{ }^{T} P+P G_{i i}+\eta P E E^{T} P+\eta^{-1} F^{T} F<0 \quad(i, j=1,2,3,4), \\
G_{i j}{ }^{T} P+P G_{i j}+\eta P E E^{T} P+\eta^{-1} F^{T} F<0 \quad(i<j<4),
\end{gathered}
$$

where

$$
G_{i i}=C_{0 i}+B_{i} K_{i}, \quad G_{i j}=\frac{\left(C_{0 i}+B_{i} K_{j}\right)+\left(C_{0 j}+B_{j} K_{i}\right)}{2} .
$$

Proof. The proof of Theorem 4 is given in the Appendix.

Therefore, dynamical error system (23) is globally asymptotically stable after controller (24) is applied to response system (17). That is to say, the synchronization is realized. According to Schur complement theorem [34], we can easily transform (35) into LMI form.

Remark 5. If the orders of drive system (16) are $\alpha_{i}=1$, that is, $\dot{x}=\widetilde{A} x+f(x)$, then the synchronization between an integer order chaos and a fractional order chaos can be achieved by the controller (24).

Remark 6. Since there exists a scaling factor $\chi(\chi \in R)$, we can choose the value of $\chi$ arbitrarily to meet our needs. For example, the synchronization is realized when $\chi=1$, and antisynchronization is achieved when $\chi=-1$.

\section{Numerical Simulation}

To evaluate the effectiveness of the designed synchronization method, we perform three typical examples in this section. The simulation results are modeled in MATLAB software using the fractional predictor-corrector algorithm.

Case 1. The case is as follows: synchronization between an integer order chaos and a fractional order chaos with uncertain parameters.

The integer order drive system [35] is written as

$$
\begin{gathered}
\dot{x}_{1}=a_{1}\left(y_{1}-x_{1}\right), \\
\dot{y}_{1}=\left(c_{1}-a_{1}\right) x_{1}-x_{1} z_{1}+c_{1} y_{1}, \\
\dot{z}_{1}=x_{1} y_{1}-b_{1} z_{1},
\end{gathered}
$$

where $\left(a_{1}, b_{1}, c_{1}\right)=(35,3,28)$ and the initial values are $\left(x_{1}, y_{1}, z_{1}\right)=(1,3,5)$; assume that $x_{1} \in(-d, d), d>0$.
Fractional order PMSM chaos [36] is presented as the response system:

$$
\begin{gathered}
\frac{d^{q_{1}} x_{2}}{d t^{q_{1}}}=-x_{2}+y_{2} z_{2}, \\
\frac{d^{q_{2}} y_{2}}{d t^{q_{2}}}=-y_{2}-x_{2} z_{2}+a_{2} z_{2}, \\
\frac{d^{q_{3}} z_{2}}{d t^{q_{3}}}=b_{2}\left(y_{2}-z_{2}\right),
\end{gathered}
$$

where $q_{1}=0.98, q_{2}=1$, and $q_{3}=0.99$ are the orders of the system. Figures $1(\mathrm{a})-1(\mathrm{~d})$ show the phase diagram without controller which exhibits chaotic behavior when $a_{2}=50$ and $b_{2}=4$ with the initial value $\left[x_{2}, y_{2}, z_{2}\right]^{T}=[35,0.02,0.01]^{T}$. Fractional order system (38) is bounded with $x_{2}(t) \epsilon$ $\left[-d_{1}, d_{1}\right]$ and $y_{2}(t) \in\left[-d_{2}, d_{2}\right]$, where $d_{1}=20$ and $d_{2}=25$.

According to Section 3.1, we can get the dynamical error system:

$$
\begin{gathered}
\frac{d^{q_{1}} e_{1}}{d t^{q_{1}}}=-x_{2}+y_{2} z_{2}+u_{21}(t), \\
\frac{d^{q_{2}} e_{2}}{d t^{q_{2}}}=-y_{2}-x_{2} z_{2}+a_{2} z_{2}+u_{22}(t), \\
\frac{d^{q_{3}} e_{3}}{d t^{q_{3}}}=b_{2}\left(y_{2}-z_{2}\right)+u_{23}(t) .
\end{gathered}
$$

Consider the uncertain parameters $a \in\left[a^{l}, a^{u}\right]$ and $b \in$ $\left[b^{l}, b^{u}\right]$ in system (39), where $a^{l}=49.8, a^{u}=50.2, b^{l}=$ 3.9 , and $b^{u}=4.1$, through generalized Takagi-Sugeno fuzzy model; (39) could be accurately expressed:

$$
\begin{aligned}
& R^{1}: \text { IF } x_{2}(t) \text { is } M_{1}\left(x_{1}(t)\right) \text {, THEN } d^{q} e(t) / d t^{q}= \\
& \widetilde{C_{1}} Y(t)+B_{1} u_{2}(t), \\
& R^{2}: \text { IF } x_{2}(t) \text { is } M_{2}\left(x_{1}(t)\right) \text {, THEN } d^{q} e(t) / d t^{q}= \\
& \widetilde{C_{2}} Y(t)+B_{2} u_{2}(t), \\
& R^{3}: \text { IF } y_{2}(t) \text { is } M_{3}\left(x_{2}(t)\right) \text {, THEN } d^{q} e(t) / d t^{q}= \\
& \widetilde{C_{3}} Y(t)+B_{3} u_{2}(t), \\
& R^{4}: \text { IF } y_{2}(t) \text { is } M_{4}\left(x_{2}(t)\right) \text {, THEN } d^{q} e(t) / d t^{q}= \\
& \widetilde{C_{4}} Y(t)+B_{4} u_{2}(t),
\end{aligned}
$$

where $Y(t)=\left[x_{2}(t), y_{2}(t), z_{2}(t)\right]^{T}$ and $u_{2}(t)=\left[u_{21}(t), u_{22}(t)\right.$, $\left.u_{23}(t)\right]^{T}$. Consider

$$
\begin{array}{ccc}
C_{1}=\left[\begin{array}{ccc}
-1 & 0 & 0 \\
0 & -1 & -20+a \\
0 & b & -b
\end{array}\right], & C_{2}=\left[\begin{array}{ccc}
-1 & 0 & 0 \\
0 & -1 & 20+a \\
0 & b & -b
\end{array}\right], \\
C_{3}=\left[\begin{array}{ccc}
-1 & 0 & 25 \\
0 & -1 & a \\
0 & b & -b
\end{array}\right], & C_{4}=\left[\begin{array}{ccc}
-1 & 0 & -25 \\
0 & -1 & a \\
0 & b & -b
\end{array}\right] .
\end{array}
$$

$B_{1}=B_{2}=B_{3}=B_{4}=I_{4 \times 4}(I$ is unit matrix $)$ 


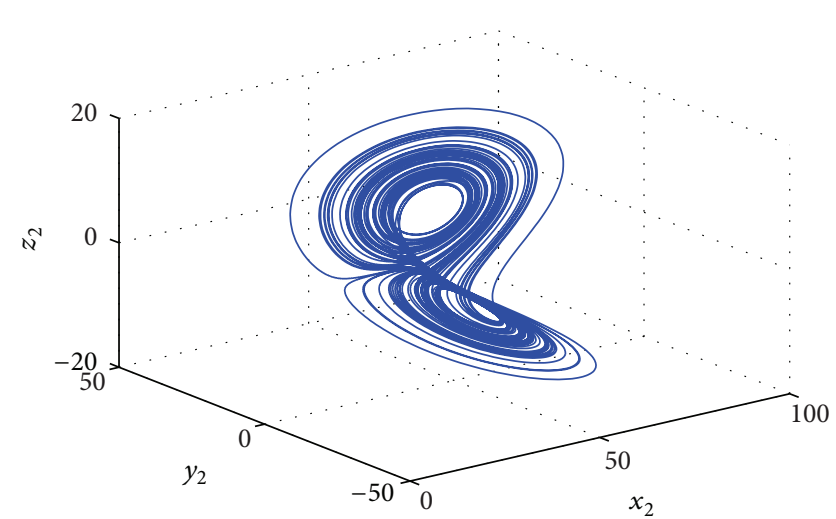

(a) State trajectory of $x_{2}-y_{2}-z_{2}$

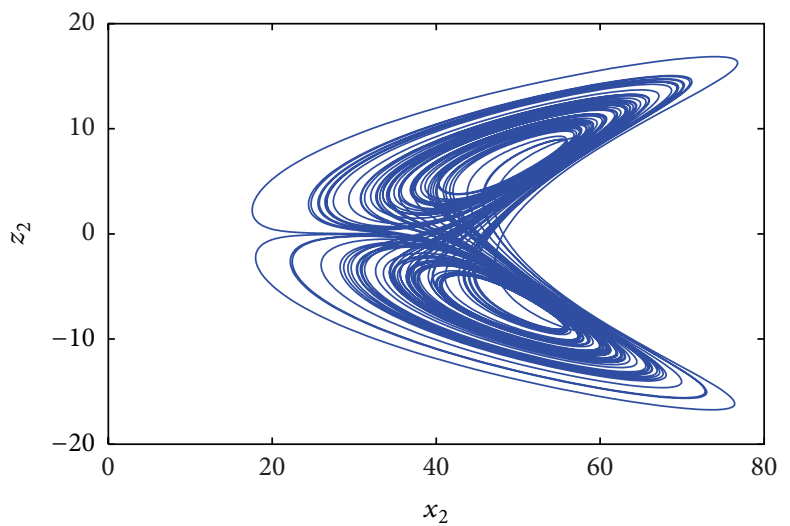

(c) State trajectory of $x_{2}-z_{2}$

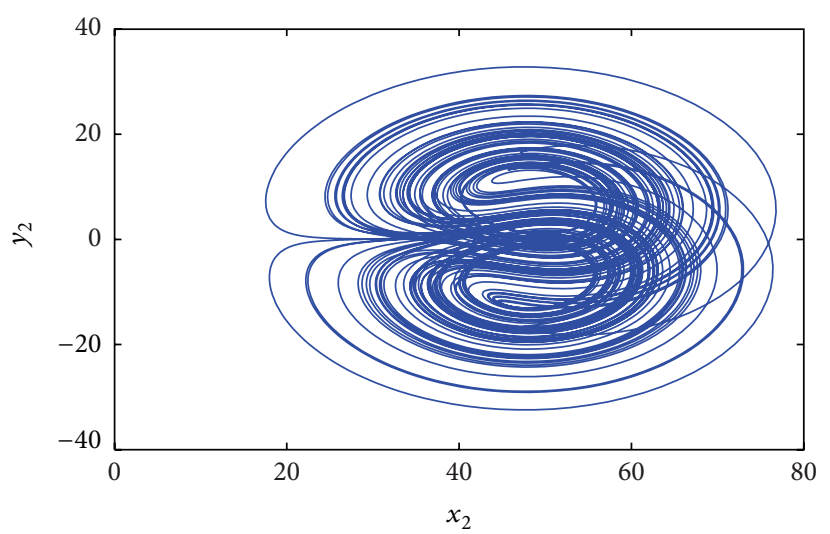

(b) State trajectory of $x_{2}-y_{2}$

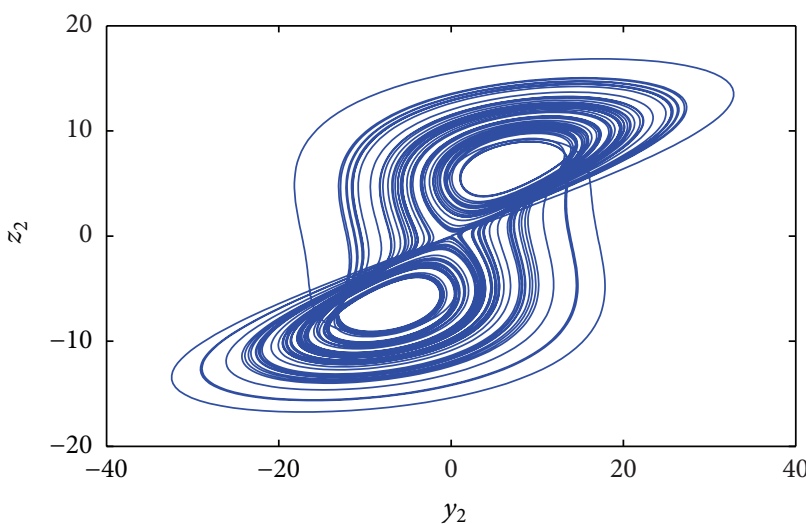

(d) State trajectory of $y_{2}-z_{2}$

FIGURE 1: Phase diagram of fractional order PMSM chaotic system (38).

We select the fuzzy sets membership function as follows:

$$
\begin{aligned}
& M_{1}\left(x_{2}(t)\right)=\frac{1}{2}\left(1+\frac{x_{2}(t)}{d_{1}}\right), \\
& M_{2}\left(x_{2}(t)\right)=\frac{1}{2}\left(1-\frac{x_{2}(t)}{d_{1}}\right), \\
& M_{3}\left(y_{2}(t)\right)=\frac{1}{2}\left(1+\frac{y_{2}(t)}{d_{2}}\right), \\
& M_{4}\left(y_{2}(t)\right)=\frac{1}{2}\left(1-\frac{y_{2}(t)}{d_{2}}\right) .
\end{aligned}
$$

Now the controller can be given in the Takagi-Sugeno fuzzy model via PDC method in Section 2.3:

$$
\begin{aligned}
& R^{1}: \operatorname{IF} x_{2}(t) \text { is } M_{1}\left(x_{2}(t)\right), \operatorname{THEN} u_{2}(t)=K_{1} Y(t), \\
& R^{2}: \operatorname{IF} x_{2}(t) \text { is } M_{2}\left(x_{2}(t)\right), \operatorname{THEN} u_{2}(t)=K_{2} Y(t), \\
& R^{3}: \operatorname{IF} y_{2}(t) \text { is } M_{3}\left(y_{2}(t)\right), \operatorname{THEN} u_{2}(t)=K_{3} Y(t), \\
& R^{4}: \operatorname{IF} y_{2}(t) \text { is } M_{4}\left(y_{2}(t)\right), \operatorname{THEN} u_{2}(t)=K_{4} Y(t) .
\end{aligned}
$$

The subcontroller $u_{2}(t)$ is obtained as

$$
u_{2}(t)=\sum_{j=1}^{r} h_{j}(z(t)) K_{j} y(t)
$$

According to Section 3.2, the dynamical error system (39) with uncertainty could be rewritten as

$$
\frac{d^{q} e}{d t^{q}}=\sum_{i=1}^{r} \sum_{j=1}^{r} h_{i}(z(t)) h_{j}(z(t))\left(C_{0 i}+E \sum F+B_{i} K_{j}\right) Y(t) .
$$

The overall control law can be got:

$$
u(t)=D^{\beta} X+\sum_{j=1}^{4} h_{j}(z(t)) K_{j} Y(t)
$$

The corresponding matrices can be given as follows. $B_{1}=B_{2}=B_{3}=B_{4}=I_{4 \times 4}(I$ is unit matrix $)$ :

$$
\begin{array}{rlrl}
C_{01} & =\left[\begin{array}{ccc}
-1 & 0 & 0 \\
0 & -1 & 30 \\
0 & 4 & -4
\end{array}\right], & C_{02}=\left[\begin{array}{ccc}
-1 & 0 & 0 \\
0 & -1 & 70 \\
0 & 4 & -4
\end{array}\right], \\
C_{03}=\left[\begin{array}{ccc}
-1 & 0 & 25 \\
0 & -1 & 50 \\
0 & 4 & -4
\end{array}\right], & C_{04}=\left[\begin{array}{ccc}
-1 & 0 & -25 \\
0 & -1 & 50 \\
0 & 4 & -4
\end{array}\right],
\end{array}
$$




$$
\begin{aligned}
E & =\left[\begin{array}{ccccccccc}
0 & 0 & 0 & 0 & 0 & 0 & 0 & 0 & 0 \\
0 & 0 & 0 & 0 & 0 & \sqrt{0.2} & 0 & 0 & 0 \\
0 & 0 & 0 & 0 & 0 & 0 & 0 & \sqrt{0.1} & \sqrt{0.1}
\end{array}\right], \\
F & =\left[\begin{array}{ccccccccc}
0 & 0 & 0 & 0 & 0 & 0 & 0 & 0 & 0 \\
0 & 0 & 0 & 0 & 0 & 0 & 0 & \sqrt{0.1} & 0 \\
0 & 0 & 0 & 0 & 0 & \sqrt{0.2} & 0 & 0 & \sqrt{0.1}
\end{array}\right]^{T}
\end{aligned}
$$

$\sum$ can be selected as $\sum=\operatorname{diag}(0.5,0.5,0.5,0.5,0.5,0.5,0.5$, $0.5,0.5)$.

According to Schur complement theorem, formula (35) can be transformed into solving linear matrix inequalities (LMIs) problem. For a given positive number $\eta=30$ and selecting $E$ and $F$ to meet the conditions of Theorem 4, the results of solution are presented as follows:

$$
\begin{gathered}
P=\operatorname{diag}(0.0335,0.0551,0.0743), \\
K_{1}=\left[\begin{array}{ccc}
0.5000 & -0.1634 & -0.2227 \\
0.0993 & -0.0368 & -32.1333 \\
0.1004 & -2.4181 & 2.5902
\end{array}\right], \\
K_{2}=\left[\begin{array}{ccc}
0.5000 & -0.0092 & -0.0170 \\
0.0056 & -0.0368 & -18.7321 \\
0.0077 & -42.0156 & 2.5902
\end{array}\right], \\
K_{3}=\left[\begin{array}{ccc}
0.5000 & 21.8219 & -10.6108 \\
-13.2636 & -0.0368 & -28.5043 \\
-6.4852 & -19.9393 & 2.5902
\end{array}\right], \\
K_{4}=\left[\begin{array}{ccc}
0.5000 & 0.0295 & 12.5229 \\
-0.0179 & -0.0368 & -26.6850 \\
5.6234 & -21.2883 & 2.5902
\end{array}\right] .
\end{gathered}
$$

By substituting the obtained $K_{1}, K_{2}, K_{3}$, and $K_{4}$ into (44), the expected controller (44) could be got. Figure 2 shows the state time domain of error system (43) with controller (44). We can clearly see when the controller is added, state responses of dynamical error system (43) can be stabilized in a finite time.

Case 2. The case is as follows: antisynchronization of two fractional order hyperchaotic systems with uncertainty and nonidentical orders.

Fractional order hyperchaotic Lorenz chaos [37] is regarded as a drive system:

$$
\begin{aligned}
& \frac{d^{\alpha} x_{1}}{d t^{\alpha}}=a_{1}\left(y_{1}-x_{1}\right)+w_{1}, \\
& \frac{d^{\alpha} y_{1}}{d t^{\alpha}}=c_{1} x_{1}-y_{1}-x_{1} z_{1},
\end{aligned}
$$

$$
\begin{aligned}
& \frac{d^{\alpha} z_{1}}{d t^{\alpha}}=-b_{1} z_{1}+x_{1} y_{1}, \\
& \frac{d^{\alpha} \omega_{1}}{d t^{\alpha}}=-y_{1} z_{1}-r_{1} w_{1}
\end{aligned}
$$

where $a_{1}, b_{1}, c_{1}, r_{1}$ are the system parameters, $\left(a_{1}, b_{1}, c_{1}, r_{1}\right)=$ $(10,8 / 3,28,1)$, and the fractional order is $\alpha=0.98$ and its initial conditions are $\left(x_{1}, y_{1}, z_{1}, w_{1}\right)=(0,3,19,0)$; assume that $x_{1} \in(-d, d), d>0$.

The fractional order hyperchaotic Chen system [38] is taken as a response system:

$$
\begin{gathered}
\frac{d^{\beta} x_{2}}{d t^{\beta}}=a_{2}\left(y_{2}-x_{2}\right), \\
\frac{d^{\beta} y_{2}}{d t^{\beta}}=r_{2} x_{2}+c_{2} y_{2}-x_{2} z_{2}-w_{2}, \\
\frac{d^{\beta} z_{2}}{d t^{\beta}}=x_{2} y_{2}-b_{2} z_{2}, \\
\frac{d^{\beta} \omega_{2}}{d t^{\beta}}=x_{2}+k,
\end{gathered}
$$

where $\beta=0.9$ is orders of the system. Figures 3(a) $-3(d)$ show the phase diagram without controller which exhibits chaotic behavior when $[a, b, c, r, k]=[36,3,28,-16,0.5]$ with initial value $\left[x_{2}, y_{2}, z_{2}, w_{2}\right]=[4,5,6,3]$. Fractional order system (48) is bounded with $x_{2}(t) \in\left[-d_{1}, d_{1}\right]$, and $y_{2}(t) \in\left[-d_{2}, d_{2}\right]$, where $d_{1}=20$ and $d_{2}=25$.

According to Section 3.1, the dynamical error system could be obtained:

$$
\begin{gathered}
\frac{d^{\beta} e_{2}}{d t^{\beta}}=a_{2}\left(y_{2}-x_{2}\right)+u_{21}(t), \\
\frac{d^{\beta} e_{2}}{d t^{\beta}}=r_{2} x_{2}+c_{2} y_{2}-x_{2} z_{2}-w_{2}+u_{22}(t), \\
\frac{d^{\beta} e_{2}}{d t^{\beta}}=x_{2} y_{2}-b_{2} z_{2}+u_{23}(t), \\
\frac{d^{\beta} e_{2}}{d t^{\beta}}=x_{2}+k+u_{24}(t) .
\end{gathered}
$$

Consider the uncertain parameters $a \in\left[a^{l}, a^{u}\right]$ and $b \in$ $\left[b^{l}, b^{u}\right]$ in system (49), where $a^{l}=35.8, a^{u}=36.2, b^{l}=2.9$, and $b^{u}=3.1$; the generalized Takagi-Sugeno fuzzy model of error system (49) could be rewritten as

$$
\begin{aligned}
& R^{1}: \text { IF } x_{2}(t) \text { is } M_{1}\left(x_{1}(t)\right) \text {, THEN } d^{q} e(t) / d t^{q}= \\
& \widetilde{C_{1}} Y(t)+B_{1} u_{2}(t), \\
& R^{2}: \text { IF } x_{2}(t) \text { is } M_{2}\left(x_{1}(t)\right) \text {, THEN } d^{q} e(t) / d t^{q}= \\
& \widetilde{C_{2}} Y(t)+B_{2} u_{2}(t), \\
& R^{3}: \text { IF } y_{2}(t) \text { is } M_{3}\left(x_{2}(t)\right) \text {, THEN } d^{q} e(t) / d t^{q}= \\
& \widetilde{C_{3}} Y(t)+B_{3} u_{2}(t), \\
& R^{4}: \text { IF } y_{2}(t) \text { is } M_{4}\left(x_{2}(t)\right) \text {, THEN } d^{q} e(t) / d t^{q}= \\
& \widetilde{C_{4}} Y(t)+B_{4} u_{2}(t),
\end{aligned}
$$




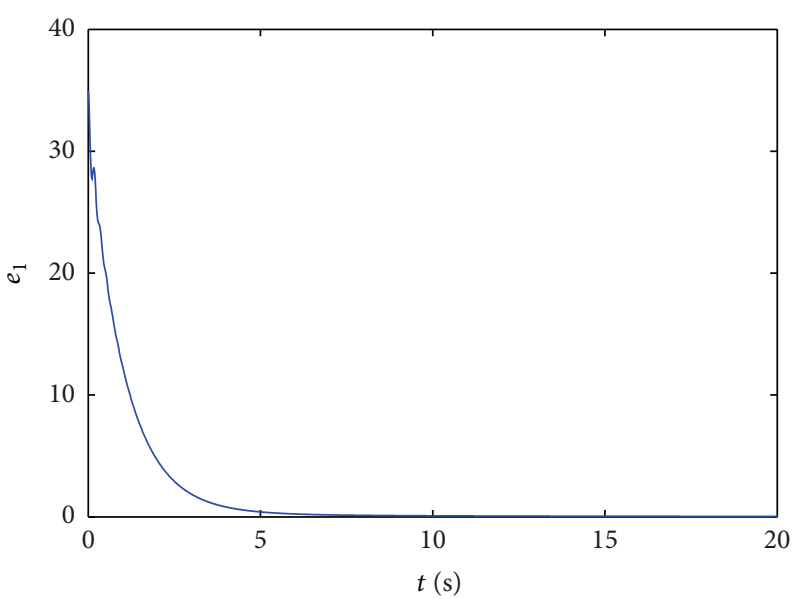

(a) State trajectory of $e_{1}$

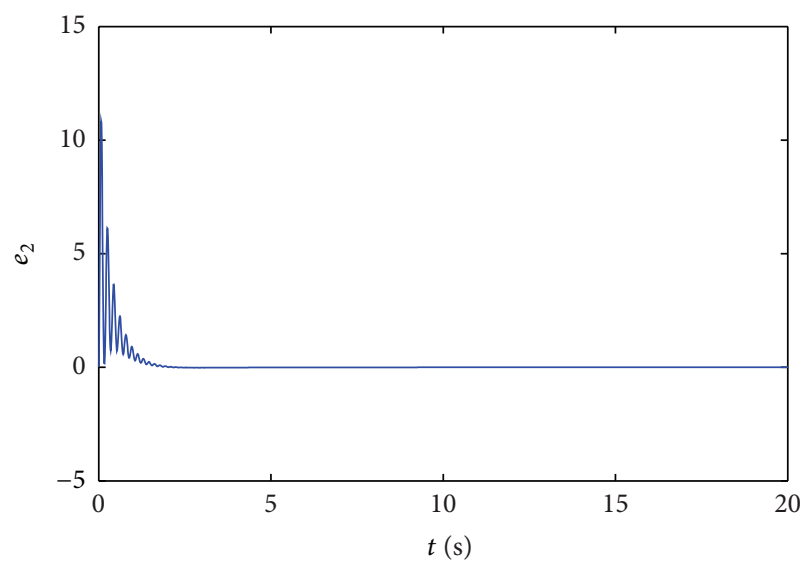

(b) State trajectory of $e_{2}$

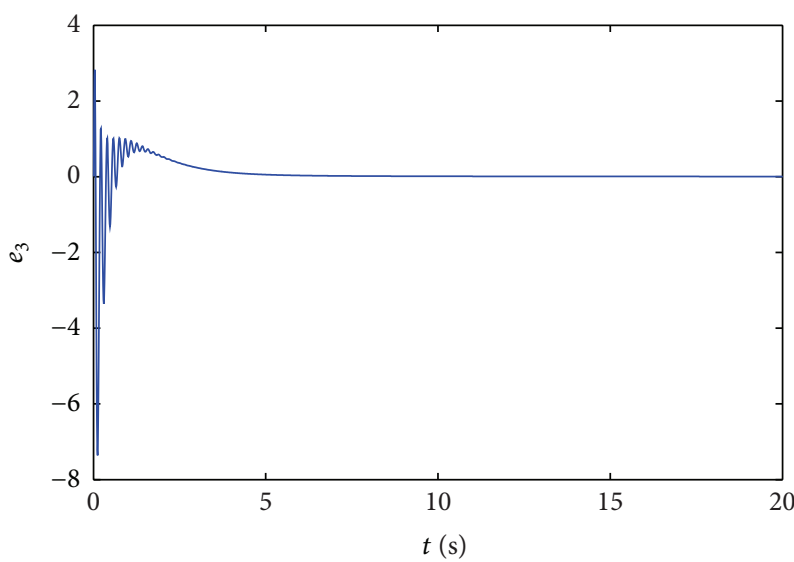

(c) State trajectory of $e_{3}$

FIGURE 2: State time domain of error system (43) with controller.

where $Y(t)=\left[x_{2}(t), y_{2}(t), z_{2}(t), w(t)\right]^{T}$ and $u_{2}(t)=\left[u_{21}(t)\right.$, $\left.u_{22}(t), u_{23}(t), u_{24}(t)\right]^{T}$. Consider

$$
\begin{aligned}
C_{1} & =\left[\begin{array}{cccc}
-a & a & 0 & 0 \\
-16 & 28 & -20 & -1 \\
0 & 20 & -b & 0 \\
1 & 0 & 0 & 0
\end{array}\right], \\
C_{2} & =\left[\begin{array}{cccc}
-a & a & 0 & 0 \\
-16 & 28 & 20 & -1 \\
0 & -20 & -b & 0 \\
1 & 0 & 0 & 0
\end{array}\right], \\
C_{3} & =\left[\begin{array}{cccc}
-a & a & 0 & 0 \\
-16 & 28 & 0 & -1 \\
25 & 0 & -b & 0 \\
1 & 0 & 0 & 0
\end{array}\right], \\
C_{4} & =\left[\begin{array}{cccc}
-a & a & 0 & 0 \\
-16 & 28 & 0 & -1 \\
-25 & 0 & -b & 0 \\
1 & 0 & 0 & 0
\end{array}\right] .
\end{aligned}
$$

$B_{1}=B_{2}=B_{3}=B_{4}=I_{4 \times 4}(I$ is unit matrix $)$.
We select the fuzzy sets membership function as follows:

$$
\begin{aligned}
& M_{1}\left(x_{2}(t)\right)=\frac{1}{2}\left(1+\frac{x_{2}(t)}{d_{1}}\right), \\
& M_{2}\left(x_{2}(t)\right)=\frac{1}{2}\left(1-\frac{x_{2}(t)}{d_{1}}\right), \\
& M_{3}\left(y_{2}(t)\right)=\frac{1}{2}\left(1+\frac{y_{2}(t)}{d_{2}}\right), \\
& M_{4}\left(y_{2}(t)\right)=\frac{1}{2}\left(1-\frac{y_{2}(t)}{d_{2}}\right) .
\end{aligned}
$$

Now the controller can be given in the Takagi-Sugeno fuzzy model via PDC method in Section 2.3:

$$
\begin{aligned}
& R^{1}: \text { IF } x_{2}(t) \text { is } M_{1}\left(x_{2}(t)\right), \text { THEN } u_{2}(t)=K_{1} Y(t), \\
& R^{2}: \text { IF } x_{2}(t) \text { is } M_{2}\left(x_{2}(t)\right) \text {, THEN } u_{2}(t)=K_{2} Y(t), \\
& R^{3}: \text { IF } y_{2}(t) \text { is } M_{3}\left(y_{2}(t)\right) \text {, THEN } u_{2}(t)=K_{3} Y(t), \\
& R^{4}: \operatorname{IF} y_{2}(t) \text { is } M_{4}\left(y_{2}(t)\right), \text { THEN } u_{2}(t)=K_{4} Y(t) .
\end{aligned}
$$




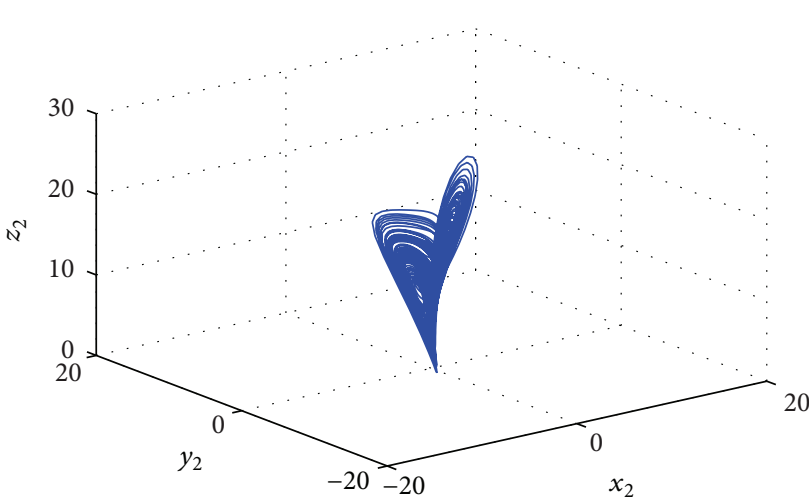

(a) State trajectory of $x_{2}-y_{2}-z_{2}$

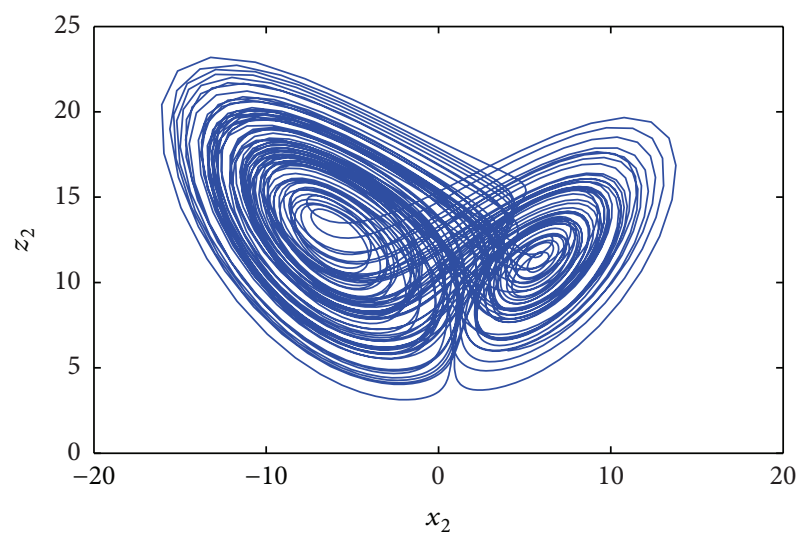

(c) State trajectory of $x_{2}-z_{2}$

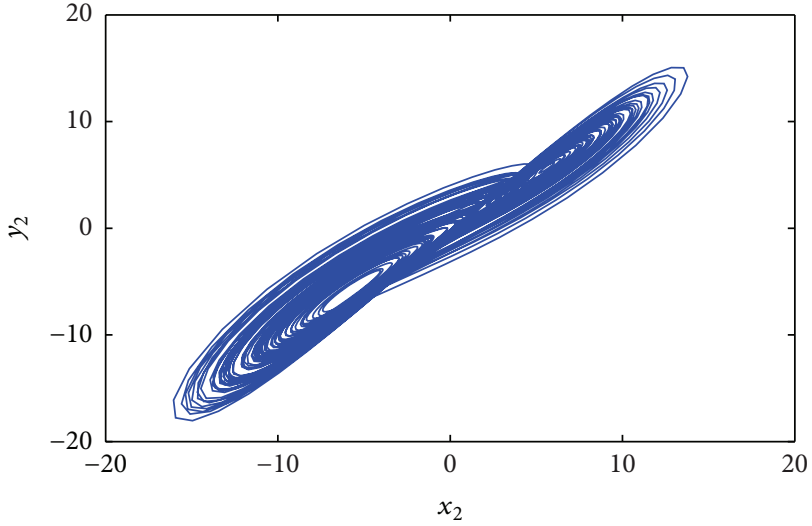

(b) State trajectory of $x_{2}-y_{2}$

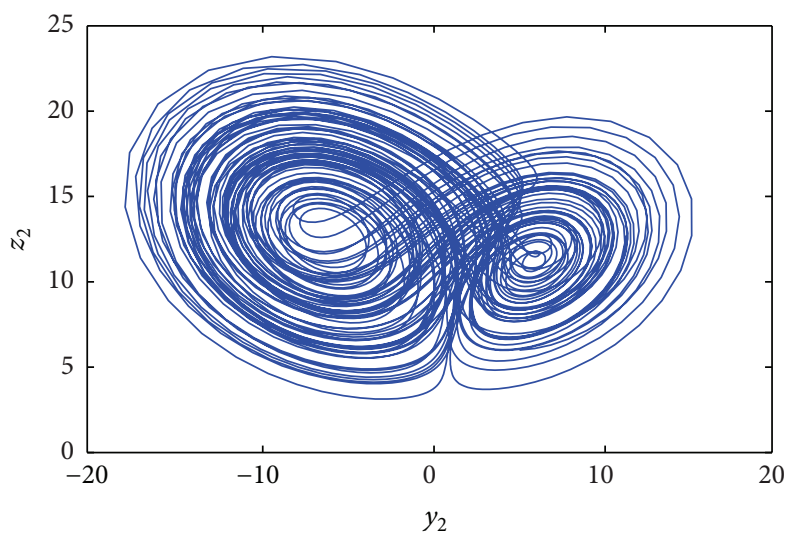

(d) State trajectory of $y_{2}-z_{2}$

FIgURE 3: Phase diagram of fractional order chaos (48).

The subcontroller $u_{2}(t)$ is obtained as

$$
u_{2}(t)=\sum_{j=1}^{r} h_{j}(z(t)) K_{j} y(t)
$$

According to Section 3.2, the dynamical error system (39) with uncertainty could be rewritten as

$$
\frac{d^{q} e}{d t^{q}}=\sum_{i=1}^{r} \sum_{j=1}^{r} h_{i}(z(t)) h_{j}(z(t))\left(C_{0 i}+E \sum F+B_{i} K_{j}\right) Y(t) .
$$

The overall control law is given by

$$
u(t)=D^{\beta}(-X)+\sum_{j=1}^{4} h_{j}(z(t)) K_{j} Y(t)
$$

The corresponding matrices can be given as follows.
$B_{1}=B_{2}=B_{3}=B_{4}=I_{4 \times 4}(I$ is the identity matrix $)$ :

$C_{01}=\left[\begin{array}{cccc}-36 & 36 & 0 & 0 \\ -16 & 28 & -20 & -1 \\ 0 & 20 & -3 & 0 \\ 1 & 0 & 0 & 0\end{array}\right]$

$C_{02}=\left[\begin{array}{cccc}-36 & 36 & 0 & 0 \\ -16 & 28 & 20 & -1 \\ 0 & -20 & -3 & 0 \\ 1 & 0 & 0 & 0\end{array}\right]$,

$C_{03}=\left[\begin{array}{cccc}-36 & 36 & 0 & 0 \\ -16 & 28 & 0 & -1 \\ 25 & 0 & -3 & 0 \\ 1 & 0 & 0 & 0\end{array}\right]$,

$C_{04}=\left[\begin{array}{cccc}-36 & 36 & 0 & 0 \\ -16 & 28 & 0 & -1 \\ -25 & 0 & -3 & 0 \\ 1 & 0 & 0 & 0\end{array}\right]$, 


$$
\begin{gathered}
E=\left[\begin{array}{cccccccccccccccc}
\sqrt{0.2} & \sqrt{0.2} & 0 & 0 & 0 & 0 & 0 & 0 & 0 & 0 & 0 & 0 & 0 & 0 & 0 & 0 \\
0 & 0 & 0 & 0 & 0 & 0 & 0 & 0 & 0 & 0 & 0 & 0 & 0 & 0 & 0 & 0 \\
0 & 0 & 0 & 0 & 0 & 0 & 0 & 0 & 0 & 0 & \sqrt{0.1} & 0 & 0 & 0 & 0 & 0 \\
0 & 0 & 0 & 0 & 0 & 0 & 0 & 0 & 0 & 0 & 0 & 0 & 0 & 0 & 0 & 0
\end{array}\right], \\
F=\left[\begin{array}{cccccccccccccccc}
\sqrt{0.2} & 0 & 0 & 0 & 0 & 0 & 0 & 0 & 0 & 0 & 0 & 0 & 0 & 0 & 0 & 0 \\
0 & \sqrt{0.2} & 0 & 0 & 0 & 0 & 0 & 0 & 0 & 0 & 0 & 0 & 0 & 0 & 0 & 0 \\
0 & 0 & 0 & 0 & 0 & 0 & 0 & 0 & 0 & 0 & \sqrt{0.1} & 0 & 0 & 0 & 0 & 0 \\
0 & 0 & 0 & 0 & 0 & 0 & 0 & 0 & 0 & 0 & 0 & 0 & 0 & 0 & 0 & 0
\end{array}\right],
\end{gathered}
$$

$\sum$ can be selected as $\sum=\operatorname{diag}(0.5,0.5,0.5,0.5,0.5,0.5,0.5$, $0.5,0.5)$.

According to Schur complement theorem, formula (35) can be transformed into solving LMIs problem. For a given positive number $\eta=10$ and selecting $E$ and $F$ to meet the conditions of Theorem 4 , the results of solution are presented as follows:

$$
\begin{gathered}
P=\operatorname{diag}(0.1951,0.1951,0.1630,0.0999), \\
K_{1}=\left[\begin{array}{cccc}
34.5689 & -97.4840 & 11.9780 & -2.4525 \\
77.4840 & -29.0410 & 61.8576 & 2.0523 \\
-14.3304 & -70.0782 & 2.0541 & -0.5901 \\
3.7874 & -2.0542 & 0.9627 & -0.5000
\end{array}\right], \\
K_{2}=\left[\begin{array}{cccc}
34.5689 & 7.4034 & 0.8774 & -2.7930 \\
-27.4034 & -29.0410 & -2.0402 & 1.3120 \\
-1.0497 & -1.4870 & 2.0541 & 0.0343 \\
4.4520 & -0.6091 & -0.0560 & -0.5000
\end{array}\right], \\
K_{3}=\left[\begin{array}{cccc}
34.5689 & -3.8880 & -23.4164 & -10.0226 \\
-16.112 & -29.041 & 0.1552 & -1.9103 \\
3.0153 & -0.1857 & 2.0541 & -0.1122 \\
18.5645 & 5.6810 & 0.1831 & -0.5000
\end{array}\right], \\
K_{4}=\left[\begin{array}{cccc}
34.5689 & -22.4474 & 10.5407 & 1.3966 \\
2.4474 & -29.0410 & -0.0161 & 0.4665 \\
12.3892 & 0.0193 & 2.0541 & -0.2996 \\
-3.7261 & 1.0414 & 0.4888 & -0.5000
\end{array}\right] .
\end{gathered}
$$

By substituting the obtained $K_{1}, K_{2}, K_{3}$, and $K_{4}$ into (54), the expected controller (54) could be got. Figure 4 shows the state time domain of error system (53) with controller (54). We can clearly see when the controller is added, state responses of dynamical error system (53) can be stabilized in a finite time which implies the anti-synchronization is achieved.

Case 3. The case is as follows: synchronization between an integer order chaos and a fractional order chaos with different dimensions and uncertain parameters.
In this case, integer order Chen system (37) and fractional order Chen hyperchaos (48) are regarded as the drive system and response system, respectively.

Now let $X=\left[x_{1}, y_{1}, z_{1}, 0\right]^{T}$ of system (37), so that we can control the state $w_{2}$ in response system (48) to zero. The dynamical error system is written as

$$
\frac{d^{q} e}{d t^{q}}=\sum_{i=1}^{r} \sum_{j=1}^{r} h_{i}(z(t)) h_{j}(z(t))\left(C_{0 i}+E \sum F+B_{i} K_{j}\right) Y(t) .
$$

The overall control law is given by

$$
u(t)=D^{\beta} X+\sum_{j=1}^{4} h_{j}(z(t)) K_{j} Y(t),
$$

where the fractional orders are $\beta=0.95$, the initial value $X=\left[x_{2}, y_{2}, z_{2}, w_{2}\right]^{T}=[4,5,6,3]^{T}$, and the other parameters are selected the same as above. Figure 5 shows the numerical simulation results, which imply the achievement of synchronization for systems (37) and (48) with different dimensions.

From the above simulations of Cases 1,2, and 3, we can clearly see when the controller was added, state responses of the dynamical error system could be stabilized in a finite time, which shows the effectiveness and robustness of the proposed scheme.

\section{Conclusions}

This paper studied the application condition of linear matrix inequality for fuzzy synchronization and antisynchronization of fractional order chaos. Based on fractional order stability theorem and generalized Takagi-Sugeno fuzzy model, one efficient stability condition for fractional order chaos synchronization and antisynchronization was given. The stability condition was transformed into a set of linear matrix inequalities and the rigorous mathematical proof was presented. And the approach was developed for fractional order chaos synchronization regardless of the system with uncertain parameters with the help of fractional order LTI interval theory. Lastly, three typical examples were employed to verify the effectiveness and robustness of the designed scheme.

\section{Appendix}

Proof of Theorem 4. According to Lemma 3, select $J_{0}=$ $y^{T} P\left(d^{q} y / d t^{q}\right)+\left(d^{q} y / d t^{q}\right)^{T} P y(P$ is a positive definite matrix $)$ as $J$ function for the error system (23). Consider

$$
\begin{aligned}
J_{0}= & y^{T} P \frac{d^{q} y}{d t^{q}}+\left(\frac{d^{q} y}{d t^{q}}\right)^{T} P y \\
=\sum_{i=1}^{4} \sum_{j=1}^{4} h_{i} h_{j} y^{T}\{[ & {\left[\left(C_{0 i}+B_{i} K_{j}\right)^{T} P+F^{T} \sum E^{T} P\right] } \\
& \left.+\left[P\left(C_{0 i}+B_{i} K_{j}\right)+P E \sum F\right]\right\} y
\end{aligned}
$$




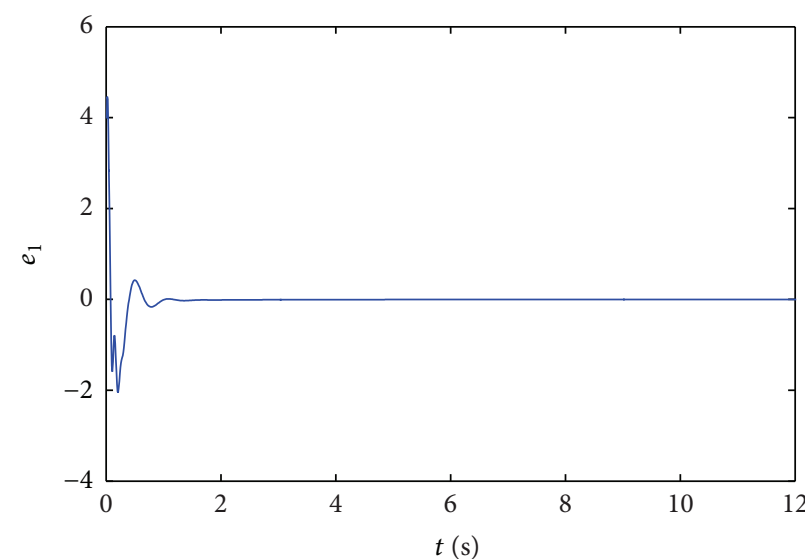

(a) State trajectory of $e_{1}$

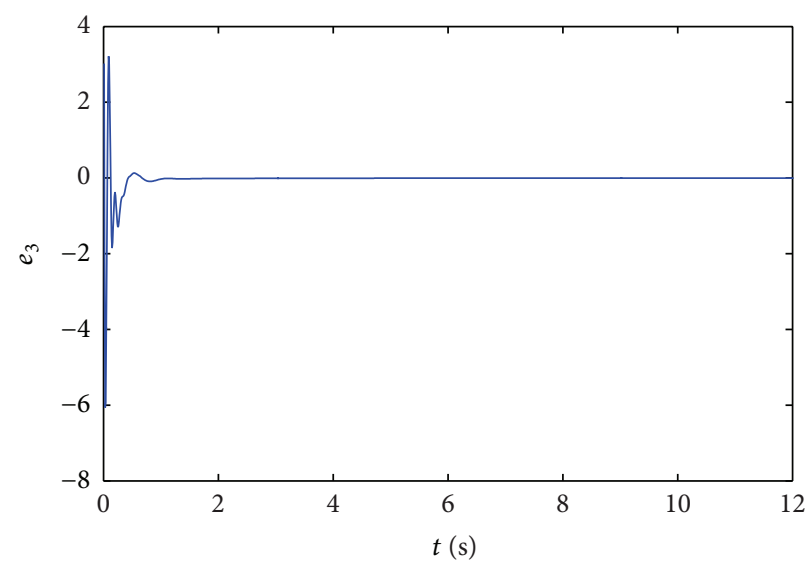

(c) State trajectory of $e_{3}$

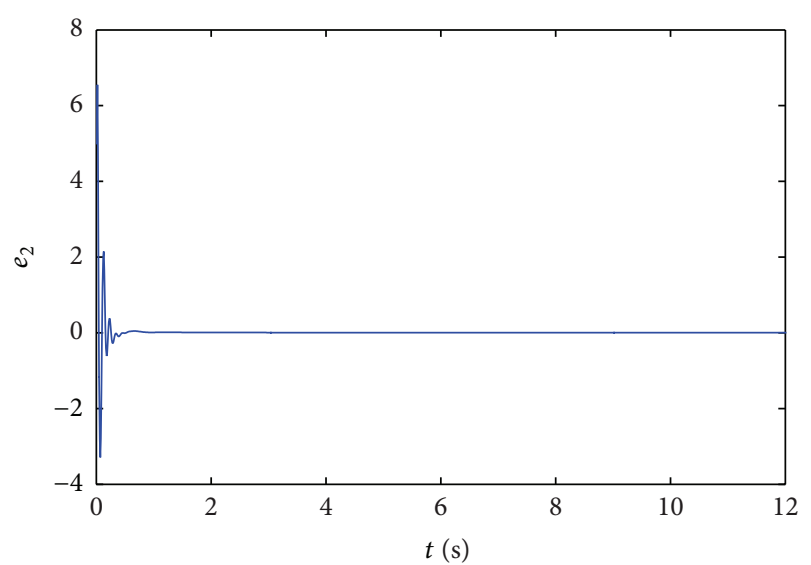

(b) State trajectory of $e_{2}$

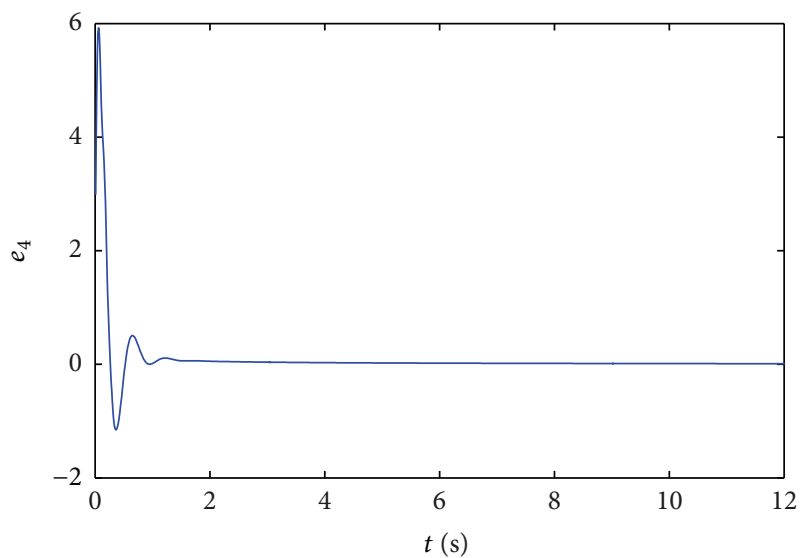

(d) State trajectory of $e_{4}$

FIGURE 4: State trajectories of error system (53) with controller.

$$
\begin{gathered}
=\sum_{i=j}^{4} h_{i}^{2} y^{T}\left[\left(C_{0 i}+B_{i} K_{i}\right)^{T} P+F^{T} \sum E^{T} P\right. \\
\left.+P\left(C_{0 i}+B_{i} K_{i}\right)+P E \sum F\right] y \\
+\sum_{i<j}^{4} h_{i} h_{j} y^{T}\left[\left(C_{0 i}+B_{i} K_{j}\right)^{T} P+F^{T} \sum E^{T} P\right. \\
\left.+P\left(C_{0 i}+B_{i} K_{j}\right)+P E \sum F\right] y \\
+\sum_{i>j}^{4} h_{i} h_{j} y^{T}\left[\left(C_{0 i}+B_{i} K_{j}\right)^{T} P+P\left(C_{0 i}+B_{i} K_{j}\right)\right. \\
\left.+F^{T} \sum E^{T} P+P E \sum F\right] y \\
=\sum_{i=1}^{4} h_{i}^{2} y^{T}\left[\left(C_{0 i}+B_{i} K_{i}\right)^{T} P+P\left(C_{0 i}+B_{i} K_{i}\right)\right] y \\
+\sum_{i=1}^{4} h_{i}^{2} y^{T}\left(F^{T} \sum E^{T} P+P E \sum F\right) y \\
+2 \sum_{i<j}^{4} h_{i} h_{j} y^{T}\left(F^{T} \sum E^{T} P+P E \sum F\right) y
\end{gathered}
$$$$
\begin{aligned}
& +\sum_{i<j}^{4} h_{i} h_{j} y^{T}\left[\left(C_{0 i}+B_{i} K_{j}\right)^{T} P+P\left(C_{0 i}+B_{i} K_{j}\right)\right] y \\
& +\sum_{i>j}^{4} h_{i} h_{j} y^{T}\left[\left(C_{0 i}+B_{i} K_{j}\right)^{T} P+P\left(C_{0 i}+B_{i} K_{j}\right)\right] y .
\end{aligned}
$$

According to the term $\sum_{i=1}^{r} h_{i}(z(t))=1$ in (7), one has

$$
\sum_{i=1}^{4} h_{i}^{2}+2 \sum_{i<j}^{4} h_{i} h_{j}=1
$$

From (A.2), one obtains

$$
\begin{aligned}
\sum_{i=1}^{4} h_{i}{ }^{2} y^{T}\left(F^{T} \sum E^{T} P+P E \sum F\right) y & \\
& +2 \sum_{i<j}^{4} h_{i} h_{j} y^{T}\left(F^{T} \sum E^{T} P+P E \sum F\right) y \\
= & y^{T}\left(F^{T} \sum E^{T} P+P E \sum F\right) y .
\end{aligned}
$$




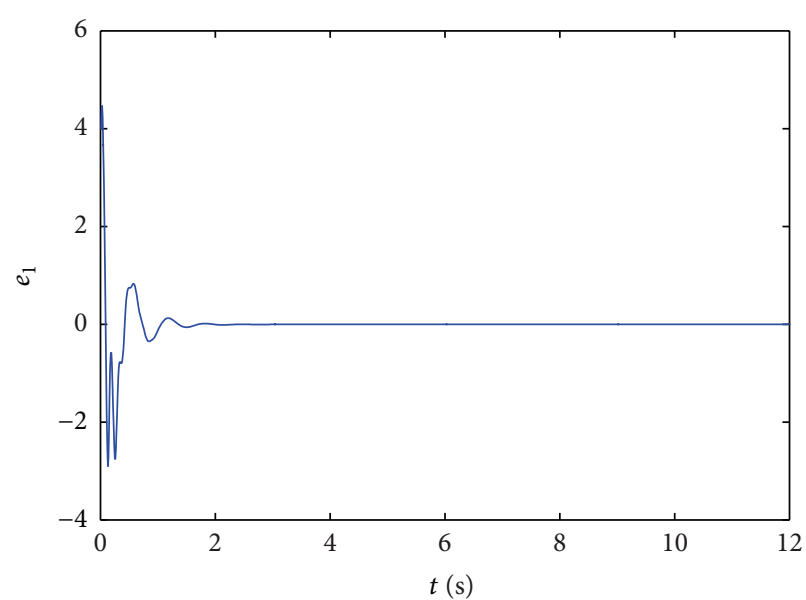

(a) State trajectory of $e_{1}$

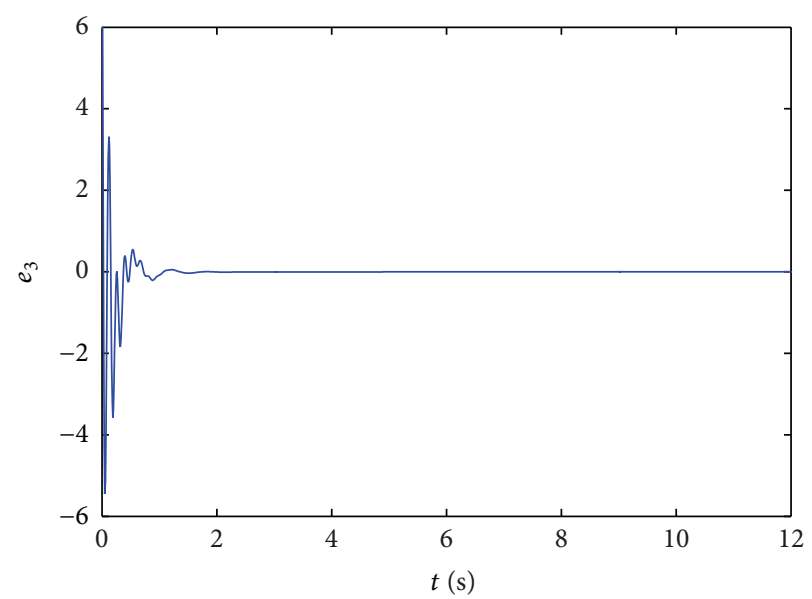

(c) State trajectory of $e_{3}$

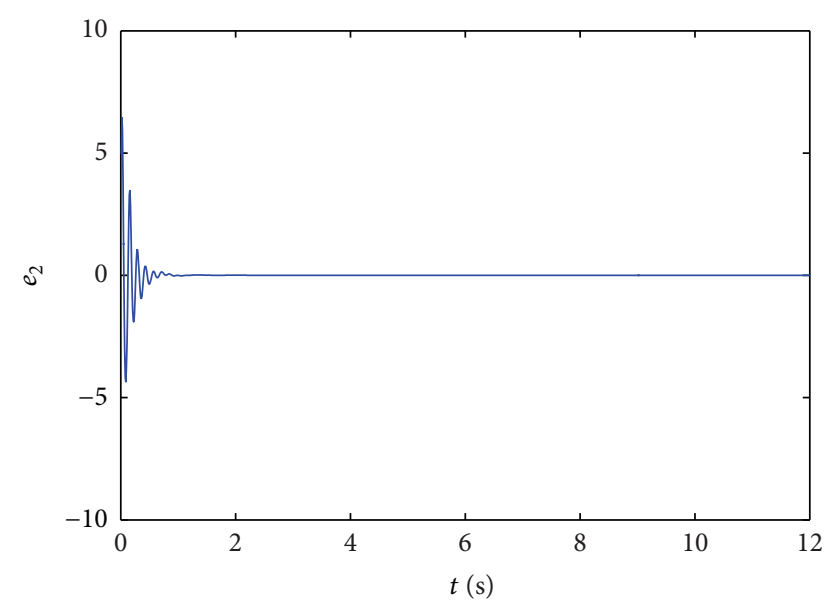

(b) State trajectory of $e_{2}$

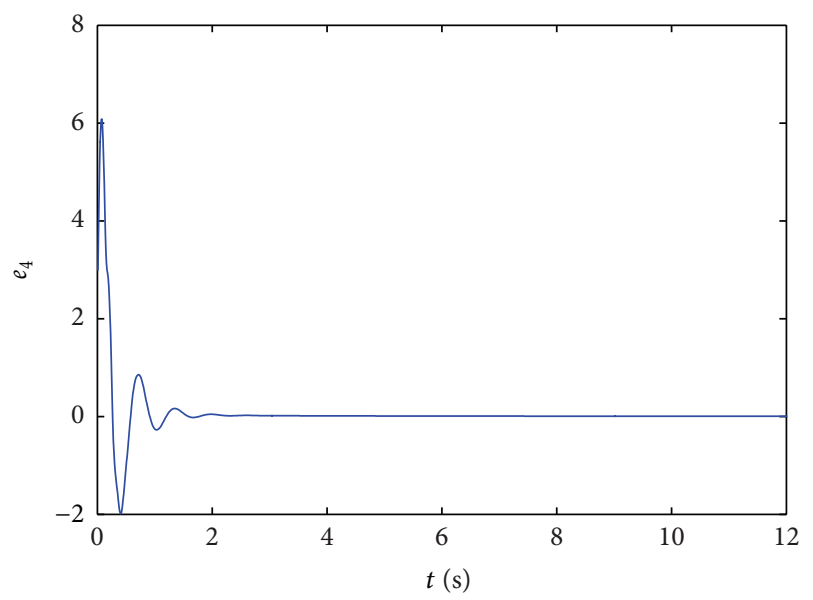

(d) State trajectory of $e_{4}$

FIGURE 5: State trajectories of error system (57) with controller.

For the following term in (A.1), one has

$$
\begin{aligned}
\sum_{i<j}^{4} h_{i} h_{j} y^{T}\left[\left(C_{0 i}+B_{i} K_{j}\right)^{T} P+P\left(C_{0 i}+B_{i} K_{j}\right)\right] y & \\
+ & \sum_{i>j}^{4} h_{i} h_{j} y^{T}\left[\left(C_{0 i}+B_{i} K_{j}\right)^{T} P+P\left(C_{0 i}+B_{i} K_{j}\right)\right] y \\
=\sum_{i<j}^{4} h_{i} h_{j} y^{T}\left\{\left[\left(C_{0 i}+B_{i} K_{j}\right)+\left(C_{0 j}+B_{j} K_{i}\right)\right]^{T} P\right. & \left.+P\left[\left(C_{0 j}+B_{j} K_{i}\right)+\left(C_{0 j}+B_{j} K_{i}\right)\right]\right\} y \\
=2 \sum_{i<j}^{4} h_{i} h_{j} y^{T}\{ & \left\{\frac{\left(C_{0 i}+B_{i} K_{j}\right)+\left(C_{0 j}+B_{j} K_{i}\right)}{2}\right]^{T} P \\
& \left.+P\left[\frac{\left(C_{0 i}+B_{i} K_{j}\right)+\left(C_{0 j}+B_{j} K_{i}\right)}{2}\right]\right\} y .
\end{aligned}
$$

Select

$$
\begin{gathered}
G_{i i}=C_{0 i}+B_{i} K_{i} \\
G_{i j}=\frac{\left(C_{0 i}+B_{i} K_{j}\right)+\left(C_{0 j}+B_{j} K_{i}\right)}{2} \quad(1 \leq i<j \leq 4) .
\end{gathered}
$$

Substituting (A.3), (A.4), and (A.5) into (A.1), one obtains

$$
\begin{aligned}
J_{0}= & \sum_{i=1}^{4} h_{i}{ }^{2} y^{T}\left(G_{i i}{ }^{T} P+P G_{i i}\right) y \\
& +2 \sum_{i<j}^{4} h_{i} h_{j} y^{T}\left(G_{i j}{ }^{T} P+P G_{i j}\right) y \\
& +y^{T} F^{T} \sum E^{T} P y+y^{T} P E \sum F y .
\end{aligned}
$$

From Lemma 1, select

$$
\begin{aligned}
& X=y^{T} P E, \\
& Y=\sum F y, \\
& R=y^{T} P E .
\end{aligned}
$$


One gets

$$
\begin{aligned}
& y^{T} F^{T} \sum E^{T} P y+y^{T} P E \sum F y \\
& \leq \eta y^{T} P E E^{T} P y+\eta^{-1} y^{T} F^{T} \sum^{T} \sum F y \\
& \quad \leq y^{T}\left(\eta P E E^{T} P+\eta^{-1} F^{T} F\right) y .
\end{aligned}
$$

By substituting (A.8) into (A.6), one has

$$
\begin{aligned}
J_{0} \leq & \sum_{i=1}^{4} h_{i}^{2} y^{T}\left(G_{i i}^{T} P+P G_{i i}\right) y \\
& +2 \sum_{i<j}^{4} h_{i} h_{j} y^{T}\left(G_{i j}{ }^{T} P+P G_{i j}\right) y \\
& +y^{T}\left(\eta P E E^{T} P+\eta^{-1} F^{T} F\right) y .
\end{aligned}
$$

By applying (A.2) to (A.9), one gets

$$
\begin{aligned}
J_{0} \leq & \sum_{i=1}^{4} h_{i}{ }^{2} y^{T}\left(G_{i i}{ }^{T} P+P G_{i i}+\eta P E E^{T} P+\eta^{-1} F^{T} F\right) y \\
& +2 \sum_{i<j}^{4} h_{i} h_{j} y^{T}\left(G_{i j}{ }^{T} P+P G_{i j}+\eta P E E^{T} P+\eta^{-1} F^{T} F\right) y .
\end{aligned}
$$

Therefore, when (35) holds, one gets

$$
J_{0}=y^{T} P \frac{d^{q} y}{d t^{q}}+\left(\frac{d^{q} y}{d t^{q}}\right)^{T} P y \leq 0 .
$$

\section{Conflict of Interests}

The authors declare that there is no conflict of interests regarding the publication of this paper.

\section{Acknowledgments}

This work was supported by the "948" Project from the Ministry of Water Resources of China (201436), the Twelfth Fiveyear National Key Technology Research and Development Program of the Ministry of Science and Technology of China (Grant no. 2011BAD29B02), the National Natural Science Foundation (51479173), and Yangling Demonstration Zone Technology Project (Grant no. 2014NY-32).

\section{References}

[1] M. R. Peterson and C. Nayak, "Effects of landau level mixing on the fractional quantum hall effect in monolayer grapheme," Physical Review Letters, vol. 113, no. 8, 5 pages, 2014.

[2] G. Maione, "On the Laguerre rational approximation to fractional discrete derivative and integral operators," IEEE Transactions on Automatic Control, vol. 58, no. 6, pp. 1579-1585, 2013.
[3] B. E. Feldman, B. Krauss, J. H. Smet, and A. Yacoby, "Unconventional sequence of fractional quantum hall states in suspended graphene," Science, vol. 337, no. 6099, pp. 1196-1199, 2012.

[4] X.-L. Ding and Y.-L. Jiang, "Analytical solutions for the multiterm time-space fractional advection-diffusion equations with mixed boundary conditions," Nonlinear Analysis: Real World Applications, vol. 14, no. 2, pp. 1026-1033, 2013.

[5] D. Y. Chen, R. F. Zhang, X. Z. Liu, and X. Y. Ma, "Fractional order Lyapunov stability theorem and its applications in synchronization of complex dynamical networks," Communications in Nonlinear Science and Numerical Simulation, vol. 19, no. 12, pp. 4105-4121, 2014.

[6] J. M. Yu, H. Hu, S. B. Zhou, and X. R. Lin, "Generalized MittagLeffler stability of multi-variables fractional order nonlinear systems," Automatica, vol. 49, no. 6, pp. 1798-1803, 2013.

[7] F. Xu, P. Yu, and X. X. Liao, "Synchronization and stabilization of multi-scroll integer and fractional order chaotic attractors generated using trigonometric functions," International Journal of Bifurcation and Chaos, vol. 23, no. 8, Article ID 1350145, 2013.

[8] S. Ghasemi, A. Tabesh, and J. Askari-Marnani, "Application of fractional calculus theory to robust controller design for wind turbine generators," IEEE Transactions on Energy Conversion, vol. 29, no. 3, pp. 780-787, 2014.

[9] Y. Chai, L. P. Chen, R. C. Wu, and J. Sun, "Adaptive pinning synchronization in fractional-order complex dynamical networks," Physica A, vol. 391, no. 22, pp. 5746-5758, 2012.

[10] A. Flores-Tlacuahuac and L. T. Biegler, "Optimization of fractional order dynamic chemical processing systems," Industrial and Engineering Chemistry Research, vol. 53, no. 13, pp. 51105127, 2014.

[11] M. Di Paola, F. P. Pinnola, and M. Zingales, "Fractional differential equations and related exact mechanical models," Computers \& Mathematics with Applications, vol. 66, no. 5, pp. 608-620, 2013.

[12] A. E. Matouk, "Stability conditions, hyperchaos and control in a novel fractional order hyperchaotic system," Physics Letters A: General, Atomic and Solid State Physics, vol. 373, no. 25, pp. 2166-2173, 2009.

[13] X.-Y. Wang and M.-J. Wang, "Dynamic analysis of the fractional-order Liu system and its synchronization," Chaos, vol. 17, no. 3, Article ID 033106, 2007.

[14] P. Zhou, R. Ding, and Y.-X. Cao, "Multi drive-one response synchronization for fractional-order chaotic systems," Nonlinear Dynamics, vol. 70, no. 2, pp. 1263-1271, 2012.

[15] B. Wang, C. Wu, and D.-L. Zhu, "A new double-wing fractionalorder chaotic system and its synchronization by sliding mode," Acta Physica Sinica, vol. 62, no. 23, Article ID 230506, 2013.

[16] X.-Z. Jin and G.-H. Yang, "Adaptive sliding mode fault-tolerant control for nonlinearly chaotic systems against network faults and time-delays," Journal of the Franklin Institute, vol. 350, no. 5, pp. 1206-1220, 2013.

[17] X. Y. Wang and M. G. Wang, "Attaining chaos synchronization by using the non-generating partitions," Applied Mathematics Letters, vol. 25, no. 12, pp. 2312-2316, 2012.

[18] H. Du, P. Shi, and N. Lü, "Function projective synchronization in complex dynamical networks with time delay via hybrid feedback control," Nonlinear Analysis: Real World Applications, vol. 14, no. 2, pp. 1182-1190, 2013.

[19] C. L. Li, K. L. Su, and L. Wu, "Adaptive sliding mode control for synchronization of a fractional-order chaotic system," Journal of Computational and Nonlinear Dynamics, vol. 8, no. 3, Article ID 031005, 2013. 
[20] H. Sadeghian, H. Salarieh, A. Alasty, and A. Meghdari, "On the fractional-order extended Kalman filter and its application to chaotic cryptography in noisy environment," Applied Mathematical Modelling, vol. 38, no. 3, pp. 961-973, 2014.

[21] D. Chen, R. Zhang, J. C. Sprott, H. Chen, and X. Ma, "Synchronization between integer-order chaotic systems and a class of fractional-order chaotic systems via sliding mode control," Chaos, vol. 22, no. 2, Article ID 023130, 2012.

[22] G.-S. Wang, J.-W. Xiao, Y.-W. Wang, and J.-W. Yi, "Adaptive pinning cluster synchronization of fractional-order complex dynamical networks," Applied Mathematics and Computation, vol. 231, pp. 347-356, 2014.

[23] C. Luo and X. Y. Wang, "Modified function projective lag synchronization in fractional-order chaotic (hyperchaotic) systems," Journal of Vibration and Control, vol. 20, no. 10, pp. 14981511, 2014.

[24] P. Zhou and R. Ding, "An adaptive tracking control of fractionalorder chaotic systems with uncertain system parameter," Mathematical Problems in Engineering, vol. 2011, Article ID 521549, 11 pages, 2011.

[25] D.-F. Wang, J.-Y. Zhang, and X.-Y. Wang, "Synchronization of uncertain fractional-order chaotic systems with disturbance based on a fractional terminal sliding mode controller," Chinese Physics B, vol. 22, no. 4, Article ID 040507, 2013.

[26] M. Verma, J. Rajasankar, and N. R. Iyer, "Fuzzy logic controller for real-time substructuring applications," Journal of Vibration and Control, vol. 20, no. 8, pp. 1103-1118, 2014.

[27] X. Zhang and L. Mu, "Command filtered adaptive fuzzy neural network backstepping control for marine power system," Mathematical Problems in Engineering, vol. 2014, Article ID 461431, 6 pages, 2014.

[28] A. Boulkroune, A. Bouzeriba, S. Hamel, and T. Bouden, "A projective synchronization scheme based on fuzzy adaptive control for unknown multivariable chaotic systems," Nonlinear Dynamics, vol. 78, no. 1, pp. 433-447, 2014.

[29] V. Vembarasan and P. Balasubramaniam, "Chaotic synchronization of Rikitake system based on T-S fuzzy control techniques," Nonlinear Dynamics, vol. 74, no. 1-2, pp. 31-44, 2013.

[30] M. Chadli and I. Zelinka, "Chaos synchronization of unknown inputs Takagi-Sugeno fuzzy: application to secure communications," Computers \& Mathematics with Applications, vol. 68, no. 12, pp. 2142-2147, 2014.

[31] C. K. Ahn, "Takagi-Sugeno fuzzy receding horizon $\mathrm{H}_{\infty}$ chaotic synchronization and its application to the Lorenz system," Nonlinear Analysis. Hybrid Systems, vol. 9, pp. 1-8, 2013.

[32] O. I. Kosmidou, "Robust stability and performance of systems with structured and bounded uncertainties: an extension of the guaranteed cost control approach," International Journal of Control, vol. 52, no. 3, pp. 627-640, 1990.

[33] G. Si, Z. Sun, H. Zhang, and Y. Zhang, "Parameter estimation and topology identification of uncertain fractional order complex networks," Communications in Nonlinear Science and Numerical Simulation, vol. 17, no. 12, pp. 5158-5171, 2012.

[34] J. Z. Liu, Z. J. Huang, and J. Zhang, "The dominant degree and disc theorem for the Schur complement of matrix," Applied Mathematics and Computation, vol. 215, no. 12, pp. 4055-4066, 2010.

[35] T. Ueta and G. Chen, "Bifurcation analysis of Chen's equation," International Journal of Bifurcation and Chaos in Applied Sciences and Engineering, vol. 10, no. 8, pp. 1917-1931, 2000.
[36] C.-L. Li, S.-M. Yu, and X.-S. Luo, "Fractional-order permanent magnet synchronous motor and its adaptive chaotic control," Chinese Physics B, vol. 21, no. 10, Article ID 100506, 2012.

[37] S. Wang, Y. G. Yu, and M. Diao, "Hybrid projective synchronization of chaotic fractional order systems with different dimensions," Physica A, vol. 389, no. 21, pp. 4981-4988, 2010.

[38] X. J. Wu, H. T. Lu, and S. L. Shen, "Synchronization of a new fractional-order hyperchaotic system," Physics Letters. A, vol. 373, no. 27-28, pp. 2329-2337, 2009. 


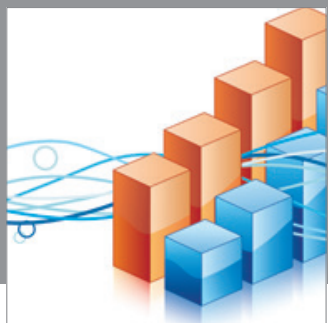

Advances in

Operations Research

mansans

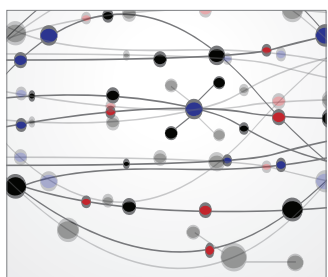

The Scientific World Journal
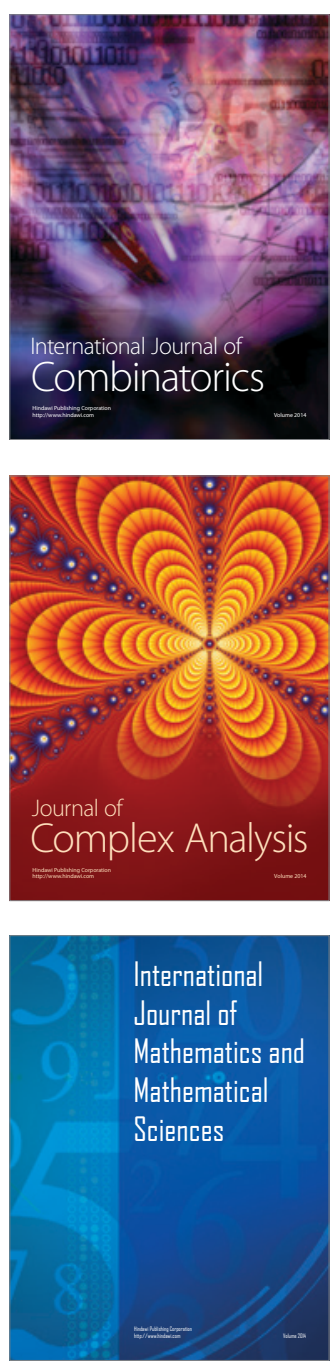
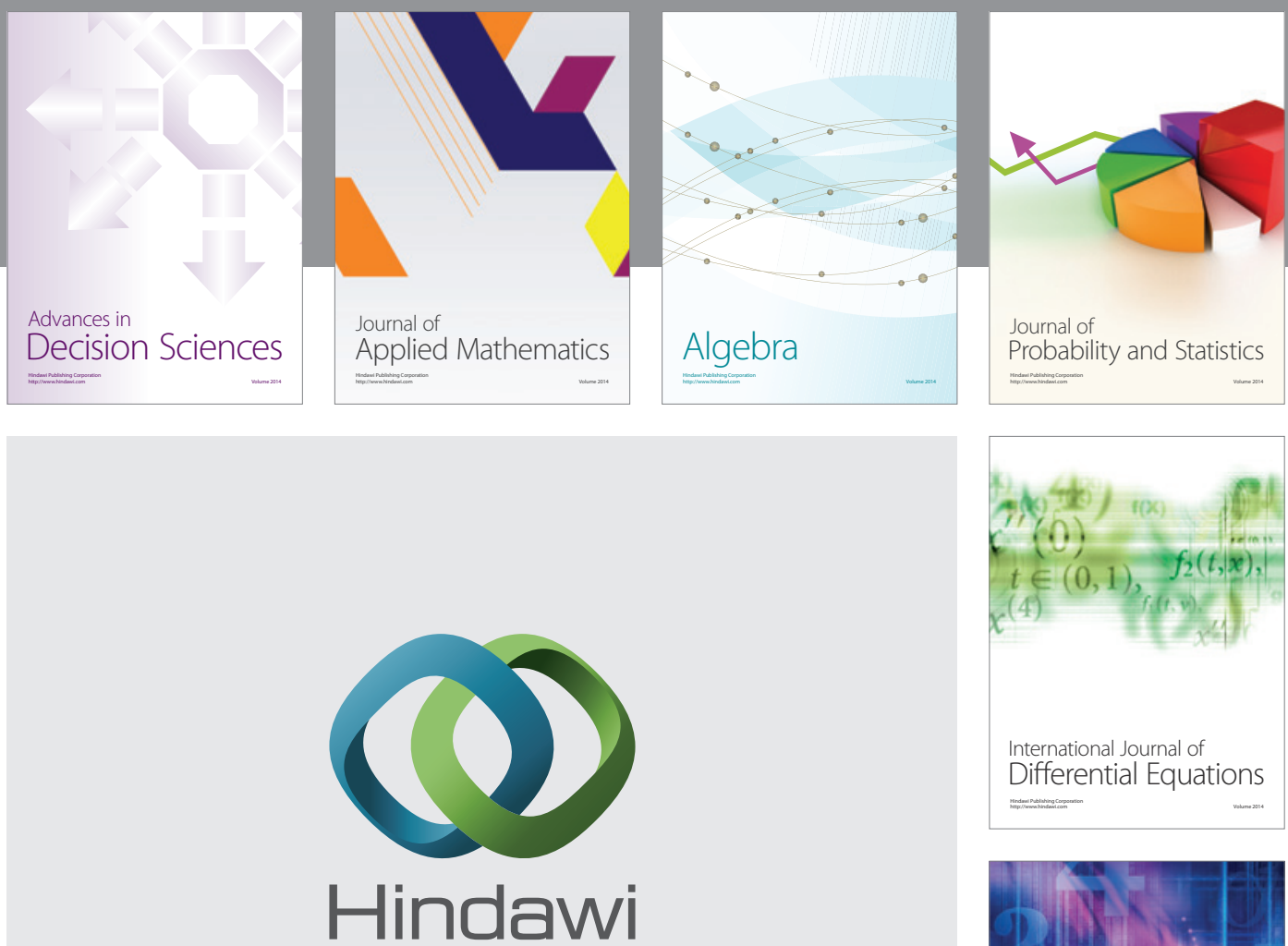

Submit your manuscripts at http://www.hindawi.com
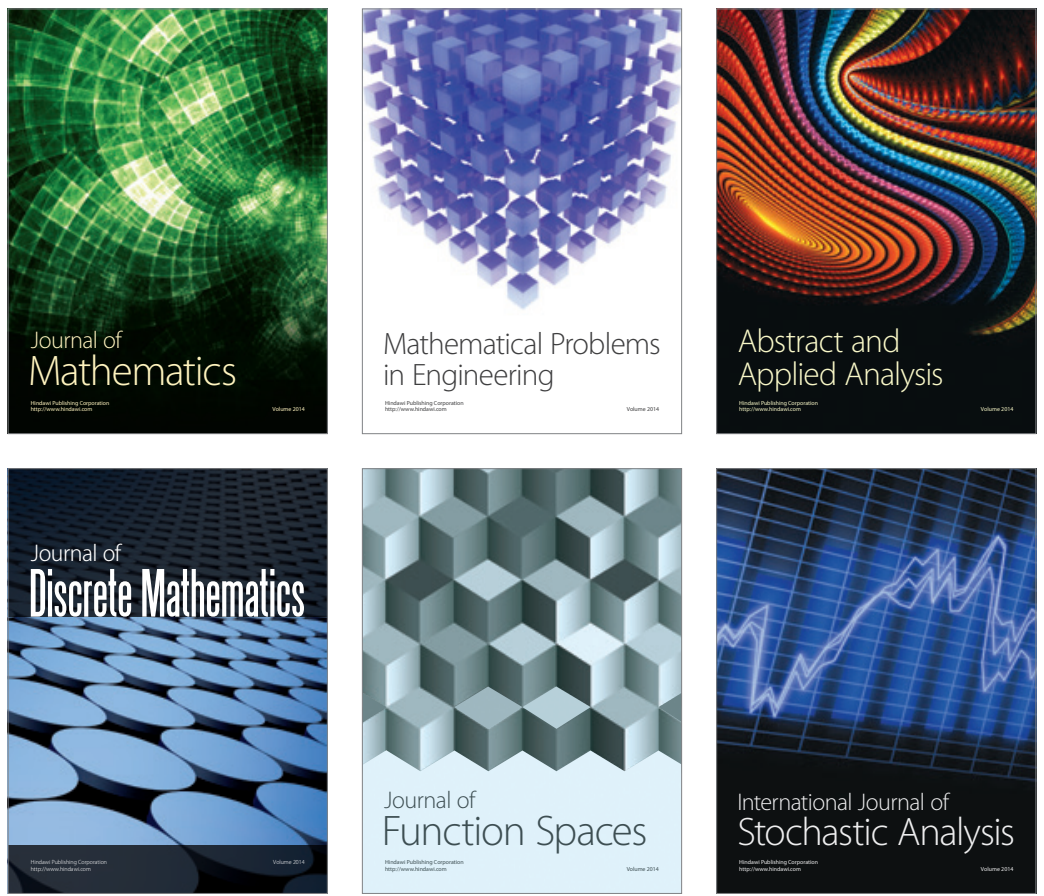

Journal of

Function Spaces

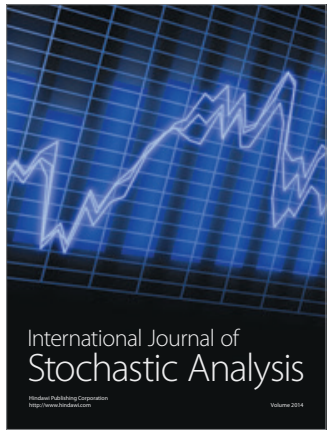

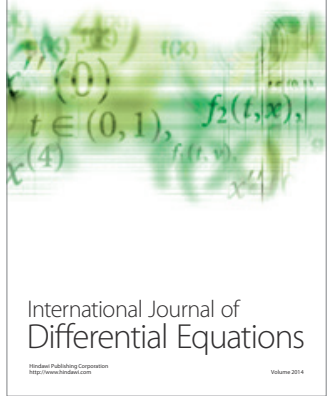
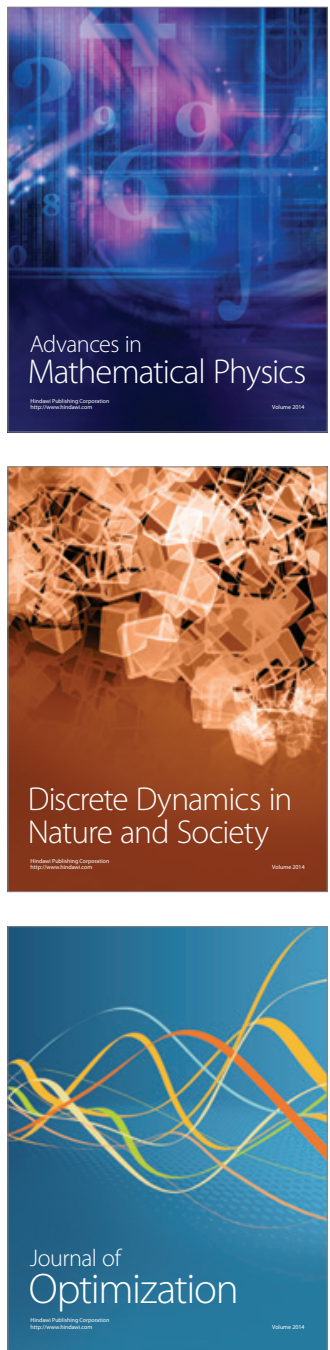